\title{
Effect of WEDM Process Parameters on Surface Roughness and Waviness of Inconel 603XL
}

\author{
K. Manikandan ${ }^{1, *}$, P. Ranjith Kumar ${ }^{2}$, S. Muthukumaran ${ }^{3}$ and B. Suresh Kumar ${ }^{4}$ \\ ${ }^{1}$ Department of Mechanical Engineering, M.A.M. College of Engineering, Trichy, Tamil Nadu, India \\ ${ }^{2}$ Department of Mechanical Engineering, M.A.M. School of Engineering, Trichy, Tamil Nadu, India \\ ${ }^{3}$ Department of Mechanical Engineering, University College of Engineering, Panruti, Tamilnadu, India \\ ${ }^{4}$ Department of Mechanical Engineering, K. Ramakrishnan College of Technology, Samyapuram, Trichy, Tamilnadu, India
}

Corresponding Author Email: *kmanidps@gmail.com

\begin{abstract}
Inconel 603 XL alloys are high-temperature superalloys focused on nickel-chromium that are commonly used in aerospace, maritime, nuclear power generation; pharmaceutical, petrochemical, and process industries. In this work, the effect of process parameters of Wire Electrical Discharge Machining (WEDM) on Inconel 603 XL's surface roughness (SR) and waviness (Wa) was studied. The Taguchi analysis and the Desirability Function Analysis (DFA) carried out single objective optimization and multi-objective optimization. From the mean roughness of the surface and the measurement of waviness, pulse on time is among the other variables most important.
\end{abstract}

Keywords: WEDM, Inconel 603 XL, surface roughness, waviness, DFA

Received: December-12-2019, Accepted: January-06-2020, https://doi.org/10.14447/jnmes.v23i1.a06

\section{INTRODUCTION}

Inconel alloys are nickel-chromium based high-temperature superalloys widely applied in aerospace, marine, nuclear power generation; chemical, petrochemical, and process industries. Execution of traditional machining operations on Inconel superalloy is quite difficult due to its very poor thermal conductivity which results in adverse thermal effects whilst machining. Inconel frequently exhibits strong work hardening behavior, high adhesion characteristics that are experienced at the tool face, and thereby alters cutting process parameters to a remarkable extent [1,2]. Additionally, Inconel may constitute particles of hard abrasives and carbides that results in severe tool wear; and, hence, surface integrity of part component appears dissatisfactory. Thus, Inconel superalloys belong to the category of 'difficult-to-cut' materials [3]. Thus, it seems indeed a great challenge to go for conventional machining on Inconel and that too by conventional cutting. Because of the difficulties faced during conventional machining, non-traditional machining routes like ElectroDischarge Machining (EDM), Wire Electro-Discharge Machining (WEDM), micro-machining (micro-electrodischarge drilling) etc. are being attempted for processing of Inconel towards achieving the desired contour with intricate geometry of the end product with reasonably good dimensional accuracy [4]. WEDM test on Inconel 601 to study the effect of peak current, duty factor, wire tension, and water pressure on surface roughness [5]. This experiment identified that surface roughness increases with the increase of peak current and the best surface finish reached is $0.8 \mu \mathrm{m}$ [6]. EDM test on Inconel $601,625,718$, and 825 to study the effect of process parameters on surface roughness. Surface roughness was found to vary from $4.9667 \mu \mathrm{m}$ to $14 \mu \mathrm{m}$ for Inconel 601 ; from $4.7 \mu \mathrm{m}$ to $11.5333 \mu \mathrm{m}$ for Inconel 625 ; from $6 \mu \mathrm{m}$ to $12.3667 \mu \mathrm{m}$ for Inconel 718 ; and from $3.7333 \mu \mathrm{m}$ to $13.2 \mu \mathrm{m}$ for Inconel 825 [7]. Therefore, the non-traditional machining of Inconel has become an important research agenda in the current context. In this work, aspects of the machinability of Inconel $603 \mathrm{XL}$ superalloys were studied. The novelty of the present work is to study the effect of WEDM process parameters on surface roughness and waviness of Inconel 603 XL. Desirability function analysis is employed to optimize the process parameter.

\section{DESIRABILITY FUNCTION ANALYSIS}

DFA is one of the most widely used methods in the industry for the optimization of multi-response problems. Desirability function analysis is used to convert the multi responses problems into single response problems. As a result, optimization of the complicated multi-response problems can be converted into the optimization of a single response problem termed as composite desirability.

\subsection{Optimization steps using Desirability Function Analysis}

Step 1: Calculate the individual desirability index (di): using the formula suggested by Derringer and Suich to determine the individual desirability index (di) for the corresponding response. There are three representations of the desirability functions according to the characteristics of the respondent.

(1). The-nominal-the best: The desirability function of the nominal-the-best can be written as the term Eq. (1). The value of $\hat{y}$ is required to achieve a particular target $\mathrm{T}$. When the $\hat{y}$ equals to $\mathrm{T}$, the desirability value equals to 1 ; if the departure of $\hat{y}$ excesses a particular range from the target, the 
desirability value equals to 0 and, such situation represents the worst case.

$$
d_{i}= \begin{cases}\left(\frac{\hat{y}-y_{\text {min }}}{T-y_{\text {min }}}\right)^{s}, & y_{\text {min }} \leq \hat{y} \leq T, \quad s \geq 0 \\ \left(\frac{\hat{y}-y_{\text {max }}}{T-y_{\text {max }}}\right)^{t}, & T \leq \hat{y} \leq y_{\text {max }}, \quad t \geq 0 \\ 0, & \text { otherwise }\end{cases}
$$

where, the $y_{\max }$ and $y_{\min }$ represent the upper/lower tolerance limits of $\hat{y}$ and, $\mathrm{s}$ and $\mathrm{t}$ represent the weights.

(2). The-larger-the better: The desirability function of thelarger-the better can be written as the term Eq. (2). The value $\hat{y}$ is expected to be the larger the better.

$$
d_{i}= \begin{cases}0, & \hat{y} \leq y_{\text {min }} \\ \left(\frac{\hat{y}-y_{\text {min }}}{y_{\text {max }}-y_{\text {min }}}\right), y_{\text {min }} \leq \hat{y} \leq y_{\text {max }}, & r \geq 0 \\ 1, & \hat{y} \geq y_{\text {min }}\end{cases}
$$

where, the $y_{\min }$ represents the lower tolerance limit of $\hat{y}$, the $\mathrm{y}_{\max }$ represents the upper tolerance limit of $\hat{y}$ and $\mathrm{r}$ represents the weight.

When the $\hat{y}$ exceed a particular criteria value, which can be viewed as the requirement, the desirability value equals to 1 ; if the $\hat{y}$ is less than a particular criteria value, which is unacceptable, the desirability value equals to 0 .

(3). The-smaller-the-better: The desirability function of the-smaller-the-better can be written as the term Eq. (3). The value $\hat{y}$ is expected to be the smaller the better. When the $\hat{y}$ is less than a particular criteria value, the desirability value equals to 1 ; if the $\hat{y}$ excess a particular criteria value, the desirability value equals to 0 .

$$
d_{i}= \begin{cases}1, & \hat{y} \leq y_{\text {min }} \\ \left(\frac{\hat{y}-y_{\max }}{y_{\min }-y_{\max }}\right), y_{\min } \leq \hat{y} \leq y_{\max }, & r \geq 0 \\ 0, & \hat{y} \geq y_{\max }\end{cases}
$$

where, the $y_{\min }$ represents the lower tolerance limit of $\hat{y}$, the $\mathrm{y}_{\max }$ represents the upper tolerance limit of $\hat{y}$ and $r$ represents the weight. The $s, t$, and $r$ in the term Eq. (1) to the term Eq. (3) indicate the weights and they are defined according to the requirement of the user. If the corresponding response is expected to be closer to the target, the weight can be set to the larger value; otherwise, it can be set to the smaller value.

Step 2: Composite desirability $(\mathrm{dG})$ calculation: The individual desirability index of all answers may be multiplied by the following equation to create a single attribute called composite desirability (dG). Eq. (4)

$$
d_{G}=\sqrt[w]{\left(d_{1} w_{1} * d_{2} w_{2} \ldots \ldots \ldots d_{i} w_{i}\right)}
$$

where $d_{i}$ is the individual desirability of the property $Y_{i}, w_{i}$ is the weight of the property " $Y_{i}$ " in the composite desirability and $\mathrm{w}$ is the sum of the individual weights.
Step 3: Determine the best possible parameter and its degree combination: The higher the desirability value of the component means the greater the consistency of the substance. Therefore the parameter impact and the optimum degree for each controllable parameter are calculated focused on the composite desirability (dG).

\section{EXPERIMENTAL SETUP}

Inconel $603 \mathrm{XL}$ is the workpiece material that is challenging to the machine in modern machining processes. Table 1 indicates the chemical composition the mechanical property is expressed in Table 2. The tests were performed as experiment architecture with 5 input variables and 2 responses with 16 runs. In this experiment, the range of process parameters used like a pulse on time, pulse off time, peak current, voltage, wire feed varies from $115-130 \mu \mathrm{s}, 40-55 \mu \mathrm{s}, 130-145 \mathrm{~A}, 15-$ $30 \mathrm{~V}, 3-6 \mathrm{~mm} / \mathrm{s}$, respectively. Zinc coated brass wire $(0.25$ $\mathrm{mm}$ diameter) is used as a substrate for wire equipment. The Surface Roughness (SR) and Waviness (Wa) responses were based on Pulse on Time (Ton), Pulse off time ( $\mathrm{T}_{\text {off }}$ ), Peak current (PI), Voltage (V) and Wire feed rate (WF).

Table 1. Chemical composition of superalloys

\begin{tabular}{cccccc}
\hline Materials/Elements & $\mathrm{Ni} \%$ & $\mathrm{Cr} \%$ & $\mathrm{Si} \%$ & $\mathrm{C} \%$ & $\mathrm{Mn} \%$ \\
\hline Inconel 603 XL & 77.4 & 15 & 2 & 0.3 & 0.3 \\
$\mathrm{Mo} \%$ & $\mathrm{Al} \%$ & $\mathrm{Ti} \%$ & $\mathrm{~B} \%$ & $\mathrm{Co} \%$ & $\mathrm{Mo} \%$ \\
4 & 0.5 & 0.5 & 0.01 & $10.0-15.0$ & 4 \\
\hline
\end{tabular}

Table 2. Mechanical properties of superalloys

\begin{tabular}{cc}
\hline Superalloys & $\begin{array}{c}\text { Inconel 603 XL } \\
\text { (nickel-chromium alloy) }\end{array}$ \\
\hline Density $\left(\mathrm{g} / \mathrm{cm}^{3}\right)$ & 8.54 \\
Tensile strength $(\mathrm{MPa})$ & 795 \\
Yield Strength $(\mathrm{MPa})$ & 420 \\
Elastic modulus $(\mathrm{GPa})$ & 218 \\
Elongation to break $(\%)$ & 30 \\
Vickers Hardness & $150-350$ \\
Thermal conductivity $\left(\mathrm{W} \mathrm{m}^{-1} \mathrm{c}^{-1}\right)$ & 11 \\
Poisson's ratio & 0.33 \\
Specific heat $\left(\mathrm{J} \mathrm{kg}^{-1} \mathrm{k}^{-1}\right)$ & 439 \\
Melting temperature $\left({ }^{\circ} \mathrm{C}\right)$ & $1380-1400$ \\
\hline
\end{tabular}

The machining was carried out on SODICK AG600L wirecut electrical discharge machine. The surface roughness and waviness of each experiment were measured using surfcom roughness and waviness tester. The roughness and waviness of each piece have been checked on three sides of the machined surface and three measurements were taken per surface. Thus, an average of 9 reading/sample was taken as the average roughness and waviness of each piece.

\section{RESULTS AND DISCUSSION}

WEDM square hole $(10 * 10 \mathrm{~mm})$ experiments have been carried out based on the L16 orthogonal array to investigate the influence of the predominant process parameters on the responses like surface roughness (SR) and Waviness (Wa). Desirability function analysis is employed in the second section of this work. 


\subsection{Effect of process parameters on SR and Wa}

\section{/ J. New Mat. Electrochem. Systems}

The experimental results are shown in Table 3. The overall mean SR, maximum SR, and minimum SR are $3.082 \mu \mathrm{m}$,
$3.763 \mu \mathrm{m}$ (experimental number 14), $2.424 \mu \mathrm{m}$ (experimental number 2) respectively. The overall mean Wa, maximum Wa, and minimum $\mathrm{Wa}$ is $2.219 \mu \mathrm{m}, 2.785 \mu \mathrm{m}$ (experimental number 14), $1.745 \mu \mathrm{m}$ (experimental number 2) respectively.

Table 3. Design and its responses

\begin{tabular}{cccccccc}
\hline \multirow{2}{*}{ Exp. No. } & & \multicolumn{3}{c}{ WEDM parameters } & & \multicolumn{2}{c}{ Responses } \\
& Pulse on time & Pulse off time & Peak current & Voltage & Wire feed & SR & Wa \\
\hline 1 & $(\mu \mathrm{s})$ & $(\mu \mathrm{s})$ & $($ Amps $)$ & $($ volt $)$ & $(\mathrm{mm} / \mathrm{s})$ & $(\mu \mathrm{m})$ & $(\mu \mathrm{m})$ \\
2 & 1 & 1 & 1 & 1 & 1 & 2.49 & 1.76 \\
3 & 1 & 2 & 2 & 2 & 2 & 2.42 & 1.74 \\
4 & 1 & 3 & 3 & 3 & 3 & 2.42 & 1.82 \\
5 & 1 & 4 & 4 & 4 & 4 & 2.46 & 1.84 \\
6 & 2 & 1 & 2 & 3 & 4 & 2.85 & 1.85 \\
7 & 2 & 2 & 1 & 4 & 3 & 2.86 & 2.03 \\
8 & 2 & 3 & 4 & 1 & 2 & 2.88 & 2.13 \\
9 & 2 & 4 & 3 & 2 & 1 & 2.87 & 2.09 \\
10 & 3 & 1 & 3 & 4 & 2 & 3.37 & 2.56 \\
11 & 3 & 2 & 4 & 3 & 1 & 3.28 & 2.24 \\
12 & 3 & 3 & 1 & 2 & 4 & 3.28 & 2.23 \\
13 & 3 & 4 & 2 & 1 & 3 & 3.33 & 2.37 \\
14 & 4 & 1 & 4 & 2 & 3 & 3.76 & 2.78 \\
15 & 4 & 2 & 3 & 1 & 4 & 3.73 & 2.72 \\
16 & 4 & 3 & 2 & 4 & 1 & 3.62 & 2.61 \\
\hline
\end{tabular}

The effect of process parameters on SR is shown in Figure 1. As pulse on-time increasing from $115 \mu$ s to $130 \mu \mathrm{s}, \mathrm{As} \mathrm{SR}$ increases. As pulse off-time increases, SR decreases up to 50 $\mu \mathrm{s}$ and increases up to $55 \mu \mathrm{s}$. As peak current increases, SR increases. As the voltage increases, SR decreases. As wire feed increases, SR increases up to $5 \mathrm{~mm} / \mathrm{s}$ and decreases up to 6 $\mathrm{mm} / \mathrm{s}$. The minimum SR was obtained at Ton at level 1, Toff at level 3, PI at level 2, V at level 3, and WF at level 1. This optimum SR condition was not performed in the designed experiment. The mean SR value represents in Table 4. The delta value represents the difference between the maximum to the minimum response. The high delta value represents the first rank order and low delta value represents the fifth rank order.

That is the delta value decreases, the rank order value decreases. From the rank analysis, Ton is the most influential factor on SR and followed by voltage. Similarly, the effect of process parameters on $\mathrm{Wa}$ is shown in Figure 2. The pulse ontime increasing from $115 \mu \mathrm{s}$ to $130 \mu \mathrm{s}$, the Wa increases. As pulse off-time increases, Wa decreases up to $50 \mu \mathrm{s}$ and increases up to $55 \mu \mathrm{s}$. As peak current increases, Wa increases. As the voltage increases, Wa decreases. As wire feed increases, Wa increases up to $5 \mathrm{~mm} / \mathrm{s}$ and decreases up to $6 \mathrm{~mm} / \mathrm{s}$. The minimum Wa were obtained at Ton at level 1, Toff at level 2, PI at level 2, V at level 3, and WF at level 4. This optimum Wa condition was not performed in the designed experiment. The mean Wa value represents in Table 5. From the rank analysis, Ton is the most influential factor in Wa and followed by the current.

Table 4. Mean SR

\begin{tabular}{cccccc}
\hline Level & $\begin{array}{c}\text { Pulse } \\
\text { on time }\end{array}$ & $\begin{array}{c}\text { Pulse } \\
\text { off time }\end{array}$ & $\begin{array}{c}\text { Peak } \\
\text { current }\end{array}$ & Voltage & $\begin{array}{c}\text { Wire } \\
\text { feed }\end{array}$ \\
\hline 1 & 2.452 & 3.121 & 3.062 & 3.113 & 3.071 \\
2 & 2.869 & 3.08 & 3.061 & 3.086 & 3.072 \\
3 & 3.321 & 3.055 & 3.104 & 3.045 & 3.1 \\
4 & 3.684 & 3.071 & 3.1 & 3.084 & 3.085 \\
Delta & 1.232 & 0.066 & 0.043 & 0.067 & 0.029 \\
Rank & 1 & 3 & 4 & 2 & 5 \\
\hline
\end{tabular}

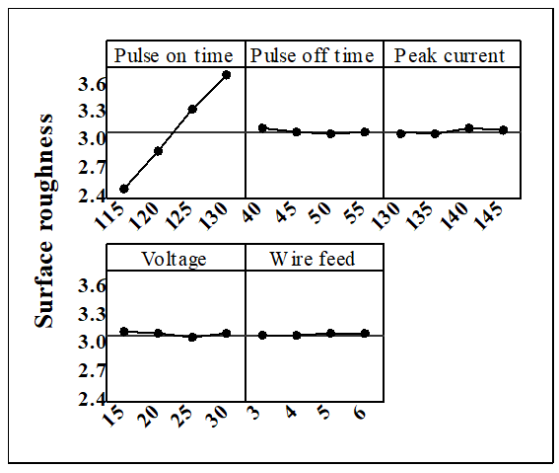

Figure 1. SR versus process parameters

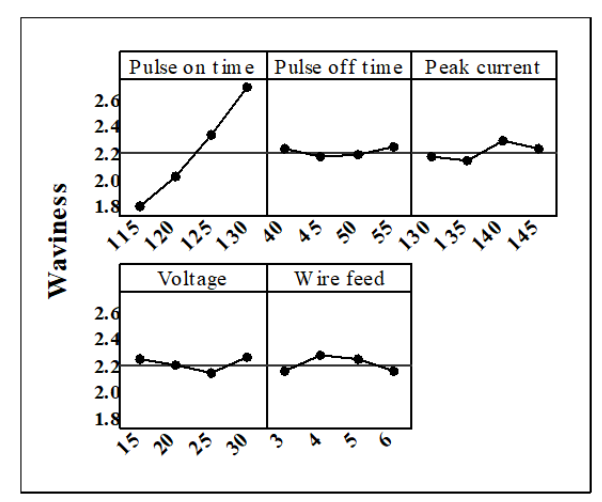

Figure 2. Wa versus process parameters

Table 5. Mean Wa

\begin{tabular}{cccccc}
\hline Level & $\begin{array}{c}\text { Pulse } \\
\text { on time }\end{array}$ & $\begin{array}{c}\text { Pulse } \\
\text { off time }\end{array}$ & $\begin{array}{c}\text { Peak } \\
\text { current }\end{array}$ & Voltage & $\begin{array}{c}\text { Wire } \\
\text { feed }\end{array}$ \\
\hline 1 & 1.796 & 2.244 & 2.186 & 2.251 & 2.171 \\
2 & 2.031 & 2.179 & 2.146 & 2.215 & 2.287 \\
3 & 2.343 & 2.2 & 2.304 & 2.147 & 2.254 \\
4 & 2.708 & 2.256 & 2.243 & 2.265 & 2.166 \\
Delta & 0.912 & 0.077 & 0.158 & 0.119 & 0.121 \\
Rank & 1 & 5 & 2 & 4 & 3 \\
\hline
\end{tabular}




\subsection{Desirability function analysis}

From the individual response analysis, the best SR is obtained at Ton at level 1, Toff at level 3, PI at level 2, V at level 3 and WF at level 1 and best Wa are obtained at Ton at level 1, Toff at level 2, PI at level 2, V at level 3 and WF at level 4. The two different optimum parameters set are obtained. To obtain the single optimum parameter set the multi-response optimization was performed. Among the different multiresponse optimization, desirability functional analysis was chosen for this work.

The assessed functional degree responses were obtained by transforming the optimization model for multi-response into a single functional category of desirability for the response. The differentiating coefficient is taken as 0.5 . The rating of each trial was tabulated depending on the functional degree of desirability and the functional degree of desirability was tested for the answers as seen in Table 6. Functional ratings of desirability for all the tests are as seen in Figure 3. It is proved from Figure 3 that experiment 2 has the optimum collection of parameters for best multi-response characteristics including SR and Wa.

The average composite desirability functional grade value for every level of the input parameters have been computed by taking the average for each level group in all the levels of process parameters and the values are given in Table 7. Since it denotes the level of correlation between the reference sequence and obtained sequence, the higher value of averaged desirability grade shows the stronger relationship between them. It clearly shows the optimal level of process parameters. The higher delta value indicates the most important nature of determining response in the cutting process. The best cutting condition is obtained at Ton at level 1, Toff at level 3, PI at level 2, $\mathrm{V}$ at level 3, and WF at level 1.
Table 6. Evaluated desirability functional analysis grade for responses

\begin{tabular}{ccccc}
\hline Order & $\begin{array}{c}\text { Individual desirability } \\
\text { SR }\end{array}$ & $\begin{array}{c}\text { Composite } \\
\text { desirability }\end{array}$ & Rank \\
\hline 1 & 0.950 & 0.977 & 0.982 & 2 \\
2 & 1.000 & 1.000 & 1.000 & 1 \\
3 & 0.996 & 0.926 & 0.980 & 3 \\
4 & 0.970 & 0.901 & 0.967 & 4 \\
5 & 0.679 & 0.894 & 0.883 & 5 \\
6 & 0.669 & 0.721 & 0.833 & 6 \\
7 & 0.658 & 0.627 & 0.802 & 8 \\
8 & 0.664 & 0.661 & 0.814 & 7 \\
9 & 0.290 & 0.212 & 0.498 & 11 \\
10 & 0.354 & 0.559 & 0.667 & 9 \\
11 & 0.359 & 0.532 & 0.661 & 10 \\
12 & 0.317 & 0.398 & 0.596 & 12 \\
13 & 0.000 & 0.000 & 0.000 & 16 \\
14 & 0.019 & 0.054 & 0.178 & 15 \\
15 & 0.101 & 0.166 & 0.360 & 13 \\
16 & 0.116 & 0.076 & 0.306 & 14 \\
\hline
\end{tabular}

Table 7. Mean GRG

\begin{tabular}{cccccc}
\hline Level & $\begin{array}{c}\text { Pulse on } \\
\text { time }\end{array}$ & $\begin{array}{c}\text { Pulse off } \\
\text { time }\end{array}$ & $\begin{array}{c}\text { Peak } \\
\text { current }\end{array}$ & Voltage & $\begin{array}{c}\text { Wire } \\
\text { feed }\end{array}$ \\
\hline 1 & 0.982 & 0.591 & 0.696 & 0.640 & 0.706 \\
2 & 0.833 & 0.670 & 0.710 & 0.619 & 0.652 \\
3 & 0.606 & 0.701 & 0.618 & 0.709 & 0.603 \\
4 & 0.211 & 0.671 & 0.609 & 0.665 & 0.672 \\
Delta & 0.771 & 0.110 & 0.101 & 0.090 & 0.103 \\
Rank & 1 & 2 & 4 & 5 & 3 \\
\hline
\end{tabular}

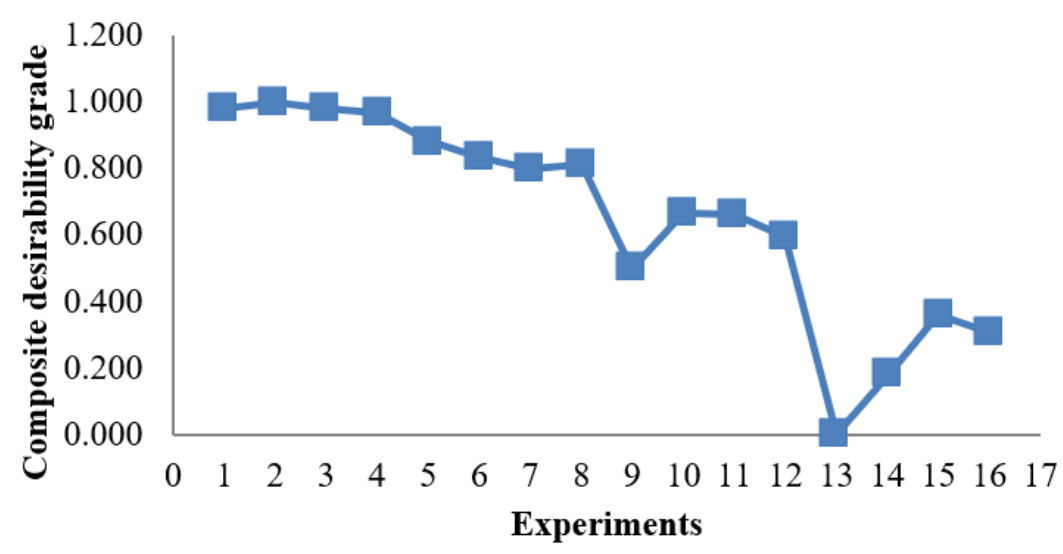

Figure 3. Composite desirability grade

\section{CONCLUSIONS}

(1) Statistical analysis shows that the pulse on time, pulse off time, and wire feed rate important factors affect the cutting of Inconel 603 XL.

(2) The best quality obtained at less than $50 \mu$ s pulse off time used.

(3) The effect of WEDM process parameters on SR and Wa of Inconel $603 \mathrm{XL}$ is similar performance to other Inconel series. (4) The Inconel $603 \mathrm{XL}$ response trends were accepted by many papers/authors.

\section{REFERENCES}

[1] Rao, R.V., Kalyankar, V.D. (2013). Parameter optimization of modern machining processes using teaching-learning-based optimization algorithm. Engineering Applications of Artificial Intelligence, 26(1): 524-531. https://doi.org/10.1016/j.engappai.2012.06.007

[2] Ashtiani, H.R.R., Zarandooz, R. (2016). Microstructural and mechanical properties of resistance spot weld of Inconel 625 supper alloy. The International Journal of Advanced Manufacturing Technology, 84(1-4): 607-619. https://doi.org/10.1007/s00170-015-7732-8 
[3] Ramanujam, R., Venkatesan, K., Saxena, V., Pandey, R., Harsha, T., Kumar, G. (2014). Optimization of Machining Parameters Using Fuzzy Based Principal Component Analysis during dry turning operation of Inconel 625-A hybrid approach. Procedia Engineering, 97: 668-676. https://doi.org/10.1016/j.proeng.2014.12.296

[4] Dinesh, S., Antony, A.G., Rajaguru, K., Vijayan, V. (2017). Experimental investigation and optimization of material removal rate and surface roughness in centerless grinding of magnesium alloy using grey relational analysis. Mechanics and Mechanical Engineering, 21(1): 17-28.

[5] Prihandana, G.S., Sriani, T., Mahardika, M., Hamdi, M., Miki, N., Wong, Y.S., Mitsui, K. (2014). Application of powder suspended in dielectric fluid for fine finish micro-EDM of Inconel 718. The International Journal of Advanced Manufacturing Technology, 75(1-4): 599-613. https://doi.org/10.1007/s00170-014-6145-4

[6] Hewidy, M.S., El-Taweel, T.A., El-Safty, M.F. (2005). Modelling the machining parameters of wire electrical discharge machining of Inconel 601 using RSM. Journal of Materials Processing Technology, 169(2): 328-336. https://doi.org/10.1016/j.jmatprotec.2005.04.078

[7] Dinesh, S., Antony, A.G., Rajaguru, K., Parameswaran, P. (2018). Comprehensive analysis of wire electric discharge machining process in machining high chromium high carbon steel. International Journal of
Mechanical and Production Engineering Research and Development (IJMPERD), 8(1): 65-74.

[8] Datta, S., Biswal, B.B., Mahapatra, S.S. (2019). Machinability analysis of Inconel 601, 625, 718 and 825 during electro-discharge machining: on evaluation of optimal parameters setting. Measurement, 137: 382-400. https://doi.org/10.1016/j.measurement.2019.01.065

[9] Tamizharasan, T., Senthilkumar, N., Selvakumar, V., Dinesh, S. (2019). Taguchi's methodology of optimizing turning parameters over chip thickness ratio in machining P/M AMMC. SN Applied Sciences, 1(2): 160. https://doi.org/10.1007/s42452-019-0170-8

[10] Dinesh, S., Pillai, T.P., Parthiban, A., Rajaguru, K. (2020). Modelling of WEDM process for machining ASTM 52100 steel. Materials Today: Proceedings. https://doi.org/10.1016/j.matpr.2020.06.343

[11] Dinesh, S., Karthikeyan, T., Vijayan, V. (2020). Powder mixed electrical discharge machining of oil hardened non shrinking steel die steel-Optimization and investigation. Materials Today: Proceedings. https://doi.org/10.1016/j.matpr.2020.04.909

[12] Dinesh, S., Rajkumar, T., Muthukumarasamy, S., Kumar, G.S., Kajendrakumar, S.V., Kumar, B.S. (2018). Analysis and optimization of Machining parameters in through Feed centerless grinding of high Carbon steel. Journal of Mechanical Engineering and Technology, 9(13): 431-441. http://www.iaeme.com/IJMET/index.asp 